\title{
Erratum to: Ontology-Based Data Access with Datalog $+/-$
}

Gerardo I. Simari, Cristian Molinaro, Maria Vanina Martinez, Thomas Lukasiewicz, and Livia Predoiu

\section{Erratum to:}

Chapter 1 in: G.I. Simari et al., Ontology-Based

Data Access Leveraging Subjective Reports, SpringerBriefs in Computer Science, https://doi.org/10.1007/978-3-319-65229-0_1

The author of the book provided the below additional reference and its respective citation for Chapter 1 after the book is published. This has now been updated in the respective chapter in the revised version of the book.

O. Tifrea-Marciuska, Personalised search for the social semantic web. D.Phil. Thesis, Department of Computer Science, University of Oxford (2016) 